Original article

\title{
Estimation of plasma levels of warfarin and 7-hydroxy warfarin by high performance liquid chromatography in patients receiving warfarin therapy
}

\author{
Dhakchinamoorthi Krishna Kumar ${ }^{\mathrm{a}, *}$, Deepak Gopal Shewade ${ }^{\mathrm{a}}$, Subramani Parasuraman ${ }^{\mathrm{a}}$, \\ Sundaram Rajan ${ }^{\mathrm{a}}$, Jayaraman Balachander ${ }^{\mathrm{b}}$, B.V. Sai Chandran ${ }^{\mathrm{c}}$, Chandrasekaran Adithan ${ }^{\mathrm{a}}$ \\ ${ }^{a}$ Department of Pharmacology, Jawaharlal Institute of Postgraduate Medical Education E Research (JIPMER), Pondicherry 605 006, India \\ ${ }^{\mathrm{b}}$ Department of Cardiology, Jawaharlal Institute of Postgraduate Medical Education E Research (JIPMER), Pondicherry 605 006, India \\ ${ }^{\mathrm{C}}$ Department of Cardiothoracic and Vascular Surgery, Jawaharlal Institute of Postgraduate Medical Education E' Research (JIPMER), Pondicherry 605 006, India
}

\section{A R T I C L E I N F O}

\section{Article history:}

Received 12 December 2012

Accepted 11 February 2013

Available online 16 March 2013

\section{Keywords:}

Carbamazepine

Metabolic ratio

Plasma concentration

Warfarin

7-Hydroxy warfarin

\begin{abstract}
A B S T R A C T
Warfarin is one of the most commonly prescribed oral anticoagulant for prevention of thromboembolic events. The effect of this drug is measured by monitoring prothrombin time expressed as International Normalized Ratio (INR). In some cases, however, the measurement of plasma concentration of warfarin was emphasized. In the present study, reversed phase high performance liquid chromatography (HPLC) was used to estimate the plasma drug levels. A total of 185 patients were enrolled in this study. Five milliliter of venous blood was collected using sodium EDTA tubes for pharmacokinetic analysis. Solid phase extraction was used to recover the warfarin and it's metabolite from plasma using isopropanol and potassium phosphate buffer (40:60) mobile phase. Warfarin, 7-hydroxy warfarin and carbamazepine (internal standard) were separated on a C18 column and had the retention time $3.6 \mathrm{~min}, 2.9 \mathrm{~min}$ and $5.9 \mathrm{~min}$, respectively. The assay was linear in warfarin concentration ranges of $0.1-5 \mu \mathrm{g} / \mathrm{ml}$. The extraction recovery was found to be $\simeq 85 \%$. The mean plasma concentrations of warfarin and 7-hydroxy warfarin were found to be $3.47 \pm 1.87$ (SD) $\mu \mathrm{g} / \mathrm{ml}, 1.25 \pm 0.81$ (SD) $\mu \mathrm{g} / \mathrm{ml}$, respectively. Through the present study the plasma concentrations of warfarin, 7-hydroxy warfarin and their metabolic ratio was determined. The assay was sensitive to follow warfarin pharmacokinetics in a patient with warfarin therapy for 3 months and above.
\end{abstract}

Copyright (c) 2013, InPharm Association, Published by Reed Elsevier India Pvt. Ltd. All rights reserved.

\section{Introduction}

Warfarin is an oral anticoagulant used in various cardiovascular and cerebrovascular disorders such as venous thromboembolism, pulmonary embolism, atrial fibrillation, valvular heart disease and coronary heart diseases. ${ }^{1-3}$ It is a drug with a narrow therapeutic index and warrants careful monitoring of the patient. Bleeding can occur as an adverse drug reaction due to increased activity of the drug at a rate of $1.3-2.7$ per 100 patient-years during the anticoagulation therapy. ${ }^{4,5}$ In order to ensure the effectiveness and safety of oral anticoagulants, the dose must be adjusted accurately and frequently. The effectiveness and safety of oral anticoagulation therapy is critically dependent on prothrombin time (PT) expressed as the International Normalized Ratio (INR), which is the time required for the blood to coagulate

\footnotetext{
* Corresponding author. Tel.: +91 0413 2296358, +91 9894465615 (mobile).

E-mail address: krishnakumarrx@hotmail.com (D. Krishna Kumar).
}

relative to the standardized coagulation time, within the desired therapeutic range. ${ }^{6}$

Currently, estimation of INR is the mainstay of monitoring warfarin therapy and it estimates its pharmacodynamic effect. However, there are several clinical studies which warrant estimation of plasma levels of warfarin and its metabolites. Further estimation of plasma drug levels may be beneficial in evaluation of drug resistance or compliance in patients. ${ }^{7}$ Several analytical methods have been developed to determine the warfarin concentration in plasma. ${ }^{8-11}$

Previous studies have been performed to measure the plasma concentrations of warfarin and its correlation with INR. However, the methods have been reported that the correlation of plasma concentrations of warfarin and warfarin mean daily dose with INR was very poor. ${ }^{11,12}$ In the present study we aimed to develop a simple, rapid, cost effective, sensitive and specific method to determine the plasma levels of warfarin and 7-hydroxy warfarin in patients who are on treatment with warfarin. 


\section{Materials and methods}

\subsection{Study setting}

The study was conducted in the out-patient clinics of cardiology and cardio thoracic and vascular surgery at Jawaharlal Institute of Postgraduate Medical Education and Research (JIPMER) hospital, Pondicherry. Institute Ethics Committee approval was obtained prior to initiation of the study. The study was approved by Institute Ethics Committee of JIPMER and the study was conducted according to declaration of Helsinki. All the study participants were explained about the study and written informed consent was obtained.

Patients receiving warfarin maintenance therapy for 3 months and above, having a stable INR of the range $2-3.5$ were included in the study. The study patients belonged to the age group of 18-65 years and of either gender. The study excluded patients with liver or renal dysfunction, concomitant drug interacting with warfarin, pregnant and lactating women, smokers and alcoholics. Patients' demographics such as age, gender, height, weight, body mass index, duration of warfarin therapy, concomitant illness status were obtained.

\subsection{Plasma warfarin determination}

\subsubsection{Sample collection and preparation}

Five $\mathrm{ml}$ of venous blood was collected into sodium Ethylene Diamine Tetra Acetic acid (EDTA) tubes from all patients, $12 \mathrm{~h}$ after the last dose of warfarin. The plasma was separated by centrifugation of blood samples at $3000 \mathrm{rpm}$ for $10 \mathrm{~min}$ and stored at $-70^{\circ} \mathrm{C}$ until analysis was done.

\subsubsection{Materials and reagents for HPLC assay}

Pure powders of warfarin, 7-hydroxy warfarin and internal standard carbamazepine were obtained from Sigma-Aldrich, St. Louis, USA. All organic solvents used were of HPLC grade and purchased from Merck specialties Pvt Ltd, Mumbai, India. Potassium di hydrogen orthophosphate and di potassium hydrogen orthophosphate were obtained from S.D. fine-chem Ltd, Mumbai, India. The C18 solid phase extraction cartridges $(100 \mathrm{mg}, 3 \mathrm{ml})$ were obtained from Varian, Inc., Agilent Technologies, USA.

\subsubsection{Preparation of standard}

The standard solution of warfarin, 7-hydroxy warfarin and internal standard carbamazepine were prepared at a concentration of $1 \mathrm{mg} / \mathrm{ml}$ in methanol. A series of six standard solutions of warfarin and 7-hydroxy warfarin were prepared in drug free human plasma at concentrations of $0.1,0.5,1.0,2.5$ and $5.0 \mu \mathrm{g} / \mathrm{ml}$. Plasma standards and quality control (QC) samples were aliquoted, stored and treated the same way as patient blood samples. The solutions for the standard curve were prepared fresh before the analysis. For estimation of drug recovery, six analytes standard water solutions were prepared by diluting the standard stock solution in MilliQ water to serve as $100 \%$ control.

\subsection{Extraction procedure}

Solid phase extraction was used to extract the drug from plasma samples. Ten microliters of $1 \mathrm{mg} / \mathrm{ml}$ internal standard (carbamazepine) was added to $1 \mathrm{ml}$ standard, QC and patient plasma samples. C18 cartridges were used for extraction. The cartridges were conditioned briefly by using $2 \mathrm{ml}$ of $1 \%$ methanol ( $\mathrm{pH} 2.8$ adjusted with orthophosphoric acid) before adding plasma. The plasma samples were rigorously vortexed and added to the conditioned columns. The warfarin and 7-hydroxy warfarin retained in the column were eluted with $2 \mathrm{ml}$ of acetonitrile. The organic phase was transferred to fresh glass tubes and evaporated to dryness under nitrogen gas in a water bath at $60{ }^{\circ} \mathrm{C}$ in sample evaporator. The samples were reconstituted with $200 \mu \mathrm{l}$ of MilliQ water. Fifty microliter of the resultant solution was injected into HPLC.

\subsection{Chromatography}

The mobile phase consisted of (40:60) isopropanol and potassium phosphate buffer (di potassium hydrogen phosphate; $\mathrm{pH} 7.0$ adjusted with potassium di hydrogen orthophosphate). The HPLC system consisted of a Shimadzu LC-10AD VP solvent delivery module, Shimadzu SPD-10A VP UV-VIS detector and a $100 \mu \mathrm{l}$ injection loop. The flow rate was maintained at $1 \mathrm{ml} / \mathrm{min}$. The analytes were detected at $308 \mathrm{~nm}$, with absorbance set at 0.005 Aufs. Separation was performed on a C18 column (Phenomenex, $150 \times 4.6 \mathrm{~mm}, 5 \mu \mathrm{m})$. Warfarin, 7-hydroxy warfarin and carbamazepine had the retention times $3.6 \mathrm{~min}, 2.9 \mathrm{~min}$ and $5.9 \mathrm{~min}$, respectively. All the chromatograms were analyzed by using the software CLASS-VP version 6.14 SP2.

To evaluate accuracy, precision and reproducibility of the method, we have estimated quality control samples containing warfarin and 7-hydroxy warfarin at the concentration ranges $0.1-$ $5.0 \mu \mathrm{g} / \mathrm{ml}$. To determine intra-day assay accuracy and precision, we performed six replicates at each of 2.5 and $5 \mu \mathrm{g} / \mathrm{ml}$. Inter-day accuracy and precision were determined over a period of 15 days using the same concentration range. The standard was analyzed on the same day of sample analysis to calculate the concentrations of warfarin and 7-hydroxy warfarin. The limit of detection was established by serial extraction of plasma samples containing decreasing concentrations of warfarin and 7-hydroxy warfarin.

\subsection{Statistical analysis}

GraphPad Instat ${ }^{\circledR}$ version 3.06 (San Diego, USA) and IBM ${ }^{\circledR}$ SPSS $^{\circledR}$ Statistics version 19.0 (SPSS Inc., Chicago, IL, USA) were used for statistical analysis. The patients were assigned into three different groups based on their maintenance dose $(\geq 2.5 \mathrm{mg}$ - low dose group, $\leq 2.5 \mathrm{mg}$ to $8.5 \mathrm{mg} \geq-$ intermediate dose group and $\geq 8.5 \mathrm{mg}-$ high dose group). The average mean plasma concentration of warfarin, 7-OH warfarin and their metabolic ratio were calculated. Warfarin metabolic ratio (MR) was compared by Mann-Whitney $U$ test. Correlation of peak area between plasma levels of warfarin and

Table 1

Demographic parameters and plasma concentration of warfarin and 7-hydroxy warfarin in study participants.

\begin{tabular}{ll}
\hline Parameters & All patients $(n=178)$ \\
\hline Age (Years) (Mean \pm SD) & $40.3 \pm 9.6$ \\
Gender & \\
$\quad$ Male (\%) & $64(36.0)$ \\
$\quad$ Female (\%) & $114(64.0)$ \\
BMI $\left(\mathrm{Kg} / \mathrm{m}^{2}\right)$ & $24.7 \pm 31.7$ \\
BSA $\left(\mathrm{m}^{2}\right)$ & $1.53 \pm 0.17$ \\
Duration of therapy (Years) & $9.6 \pm 10.4$ \\
Average daily dose of warfarin $(\mathrm{mg} \pm \mathrm{SD})$ & $4.88 \pm 1.63$ \\
Mean plasma warfarin ( $\mu \mathrm{g} / \mathrm{ml} \pm \mathrm{SD})$ & $3.47 \pm 1.87$ \\
Mean plasma 7-hydroxy warfarin $(\mu \mathrm{g} / \mathrm{ml} \pm \mathrm{SD})$ & $1.25 \pm 0.81$ \\
Indications for warfarin & \\
Rheumatic Heart Disease (Mitral stenosis) $(\%)$ & $116(65.2)$ \\
Atrial fibrillation $(\%)$ & $12(6.8)$ \\
Deep vein thrombosis $(\%)$ & $10(5.6)$ \\
Coronary Heart Disease $(\%)$ & $10(5.6)$ \\
Mitral valve replacement $(\%)$ & $7(3.9)$ \\
Pulmonary embolism $(\%)$ & $7(3.9)$ \\
Coronary artery disease $(\%)$ & $6(3.4)$ \\
Aortic valve replacement (\%) & $5(2.8)$ \\
Cardiomyopathy (\%) & $5(2.8)$ \\
\hline
\end{tabular}


7-hydroxy warfarin were estimated by linear regression analysis. A $p<0.05$ was considered statistically significant.

\section{Results}

The demographic parameters and plasma levels of warfarin and 7-hydroxy warfarin of study participants are given in Table 1 . Among 185 patient samples, 7 were excluded for analysis due to loss of samples during processing. Analysis of warfarin and 7-hydroxy warfarin by UV detection at $308 \mathrm{~nm}$, exhibits a good baseline separation (Fig. 1). A total of 178 samples were included for the analysis. The average daily maintenance dose of warfarin was calculated to be $4.88 \pm 1.63$ (SD) $\mathrm{mg}$. The patients were stratified into three different groups based on their maintenance dose ( $\geq 2.5 \mathrm{mg}-$ sensitive group, $\leq 2.5 \mathrm{mg}$ to $8.5 \mathrm{mg} \geq-$ intermediate group and $\geq 8.5 \mathrm{mg}$ - resistant group). The plasma concentration of

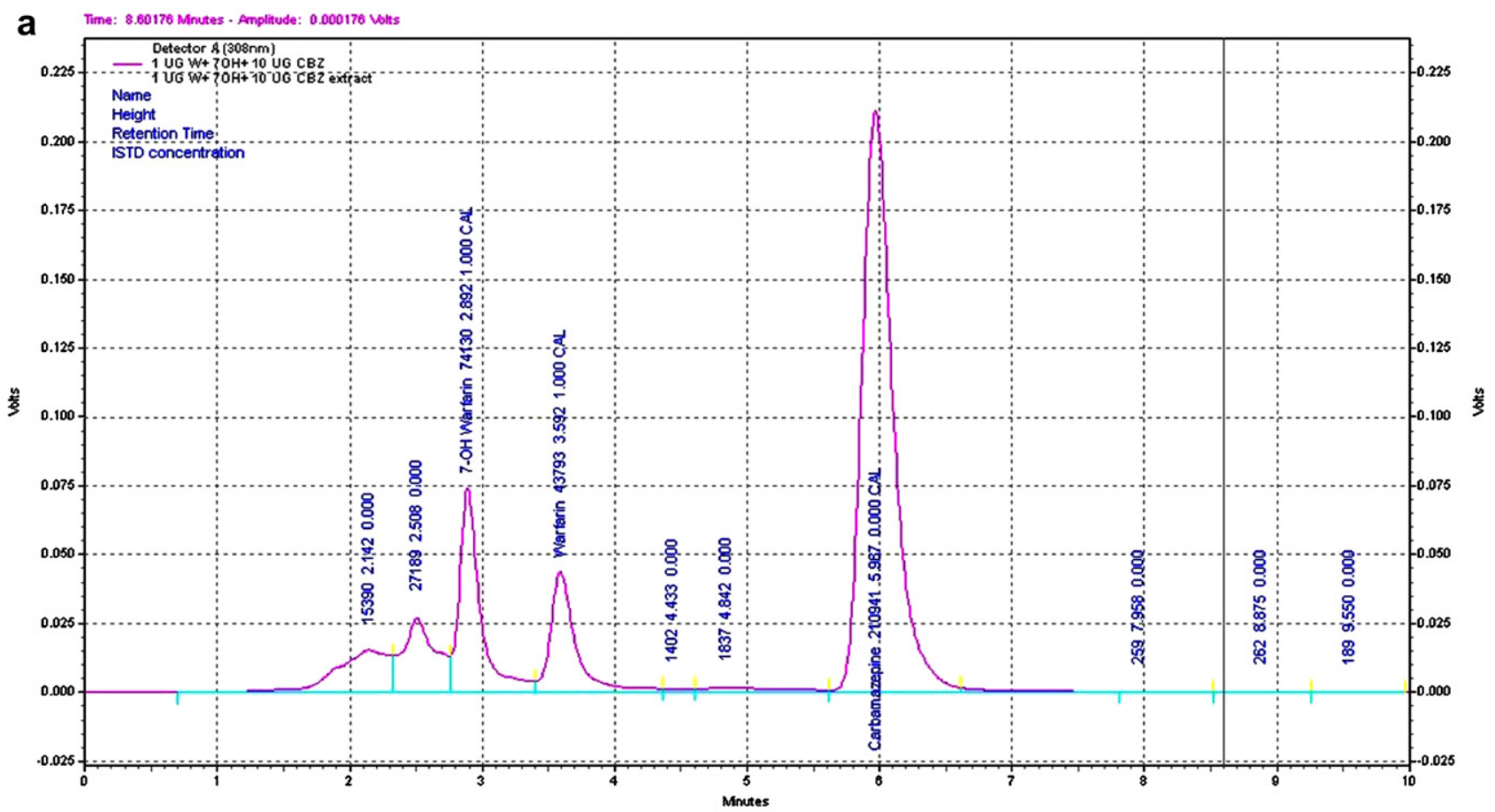

b

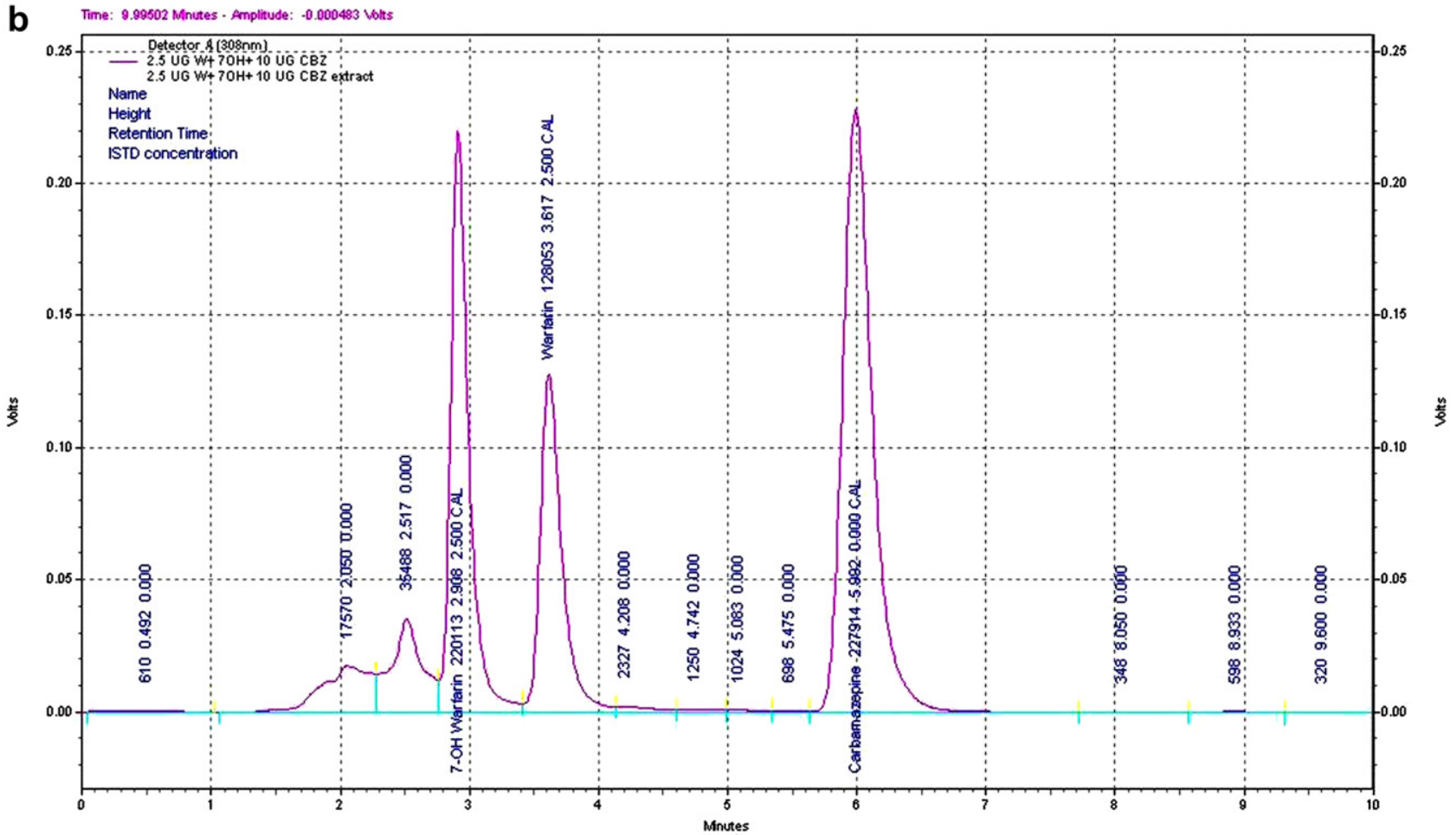

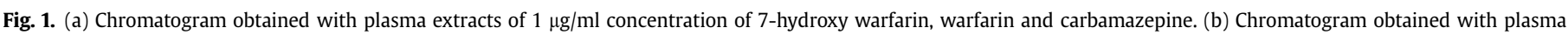
extracts of $2.5 \mu \mathrm{g} / \mathrm{ml}$ concentration of 7-hydroxy warfarin, warfarin and carbamazepine. 
Table 2

Average plasma concentration of warfarin, 7-hydroxy warfarin and metabolic ratio at different dose groups.

\begin{tabular}{|c|c|c|c|c|}
\hline Warfarin dose group & $n=178$ & Plasma warfarin $(\mu \mathrm{g} / \mathrm{ml})$ & Plasma 7-OH warfarin $(\mu \mathrm{g} / \mathrm{ml})$ & Metabolic ratio (MR) \\
\hline A Low dose group [ $\leq 2.5 \mathrm{mg} /$ day $]$ & 35 & $2.88 \pm 1.46[2.2-3.5]$ & $1.53 \pm 1.12[1.0-2.0]$ & $2.56 \pm 1.48[1.93-3.18]$ \\
\hline $\begin{array}{l}\text { B Standard dose group [ } \geq 2.5 \text { to } \\
\leq 8.5 \mathrm{mg} / \text { day] }\end{array}$ & 138 & $3.53 \pm 1.89[3.1-3.9]$ & $1.19 \pm 0.7[1.0-1.3]$ & $3.72 \pm 2.66[3.17-4.28]$ \\
\hline$C$ High dose group $[\geq 8.5 \mathrm{mg} /$ day $]$ & 5 & $6.38 \pm 1.58[2.4-10.3]$ & $0.97 \pm 0.46[0.18-2.1]$ & $7.43 \pm 2.74[0.7-14.19]$ \\
\hline
\end{tabular}

Values expressed as $-[$ mean \pm SD (95\% Confidence interval)].

Metabolic ratio - Plasma concentrations of warfarin/7-hydroxy warfarin.

$\mathrm{MR}-\mathrm{A}$ vs B $p<0.05$, B vs C $p>0.05$, A vs C $p<0.05$.

warfarin and 7-hydroxy warfarin was calculated in each group (Table 2.). The metabolic ratio of the sensitive group was significantly different from the standard dose $(p<0.001)$ and high dose groups $(p<0.05)$. The mean recoveries of 7-hydroxy warfarin and warfarin were $\simeq 88 \%$ and $\simeq 93 \%$, respectively. The relative standard deviation of inter-day variation was found to less than $8 \%$ and the intra-day variation was found to be less than $9 \%$ in the detection. The method showed less than $8 \%$ bias in the quantification (Table 3). The limit of detection was $0.1 \mu \mathrm{g} / \mathrm{ml}$ for warfarin and $0.05 \mu \mathrm{g} / \mathrm{ml}$ for 7-hydroxy warfarin. A very weak correlation was observed between plasma warfarin and 7-hydroxy warfarin $\left(r^{2}=0.07, p<0.05, Y=0.855 X+2.65 \mathrm{e}^{-2}\right)$. A moderately positive correlation was observed between peak area of warfarin and plasma warfarin concentrations $\left(r^{2}=0.65, p<0.001\right.$, $Y=1.268 X+3.437 \mathrm{e}^{-6}$ ) (Fig. 2).

\section{Discussion}

The purpose of the study was simultaneous estimation of plasma concentration of the total warfarin and its predominant metabolite 7-hydroxy warfarin and their metabolic ratio in patients receiving warfarin therapy. This method may be used in various clinical studies involving pharmacokinetics, drug interactions and pharmacogenetics. It may also be used in certain clinical scenarios where estimation of plasma levels of warfarin may be used for differentiating drug resistance from lack of compliance.

The extraction of the drug from plasma is a critical step to ensure good recovery before sample injection into the HPLC column. We used solid phase extraction with C18 cartridges and elution was done by using acetonitrile, so as to remove proteins and other plasma debris from the recovered samples. A previous pilot study ${ }^{13}$ described the measurement of warfarin and 7-hydroxy warfarin in North Indian patients in a very small sample size $(n=25)$ and they have reported that the ratio of INR and 7-hydroxy warfarin correlates better with the weekly dose of warfarin in patients on long-term anticoagulation. Also, they have reported that

Table 3

Inter-day and Intra-day variation for estimation of plasma levels of warfarin and 7hydroxy warfarin $(n=6)$.

\begin{tabular}{llll}
\hline $\begin{array}{l}\text { Nominal concentration in } \\
\text { plasma }(\mu \mathrm{g} / \mathrm{ml})\end{array}$ & $\begin{array}{l}\text { Concentration found } \\
\text { in plasma }(\mu \mathrm{g} / \mathrm{ml}) \\
(\text { mean } \pm \mathrm{SD})\end{array}$ & R.S.D. $(\%)$ & Bias $(\%)$ \\
\hline Inter-day & $2.32 \pm 0.13$ & $6.25 \%$ & -7.2 \\
Warfarin 2.5 & $2.45 \pm 0.28$ & $3.26 \%$ & -2.0 \\
7-hydroxy warfarin 2.5 & $4.79 \pm 0.28$ & $5.89 \%$ & -4.2 \\
Warfarin 5 & $4.65 \pm 0.14$ & $3.14 \%$ & -7.0 \\
7-hydroxy warfarin 5 & & & \\
Intra-day & $2.39 \pm 0.13$ & $5.52 \%$ & -5.2 \\
Warfarin 2.5 & $2.41 \pm 0.10$ & $3.61 \%$ & -3.6 \\
7-hydroxy warfarin 2.5 & $4.73 \pm 0.39$ & $8.36 \%$ & -5.4 \\
Warfarin 5 & $4.74 \pm 0.11$ & $2.39 \%$ & -5.2 \\
7-hydroxy warfarin 5 & & & \\
\hline
\end{tabular}

RSD - Relative standard deviation, Bias was calculated as (concentration found in plasma - expected concentration/expected concentration $\times 100)$. there was an extremely poor correlation between the plasma total warfarin and its metabolite (7-hydroxy warfarin) ratio and the weekly dose of warfarin $\left(r^{2}=0.02\right)$. In the present study was conducted in large sample size $(n=178)$ also the findings of our study in line with this report and we have observed a poor correlation $\left(r^{2}=0.07\right)$. Another study by Huang et $\mathrm{al}^{14}$ reported that there was a correlation between free warfarin concentration and INR $(r=0.207)$ and weekly warfarin dosage $(r=0.378)$. However other studies ${ }^{11,12}$ were shown that there was a poor correlation between the free plasma warfarin and INR, similarly the correlation between INR and weekly warfarin dose. In the present study we have included patients with stable INR values within the therapeutic range (2.0-3.5), so we have not correlated the INR values with plasma warfarin concentrations.

The previous studies have determined the various hydroxylated warfarin metabolites ${ }^{15,16}$; however, 7-hydroxy warfarin was reported to be the predominant metabolite. In the present study we measured 7-hydroxy warfarin. Further, the metabolic ratio was also calculated based on which the populations may be categories as poor, rapid and ultra-rapid metabolizers. ${ }^{17,18}$ In our previous studies we have explained the metabolic profiling for proguanil oxidation by CYP2C19, CYP2C9 induction/inhibition by phenytoin and phenytoin toxicity. ${ }^{19,20}$ In the present study the metabolic ratio was calculated and the patients were stratified based on the required daily dose of warfarin. We have observed that the high dose group showed higher metabolic ratio, this may demonstrate that the phenomenon of saturation kinetics (zero order kinetics) of warfarin when dose is increased. ${ }^{21}$ As it can be seen, when higher doses are given, the clearance is decreased and the concentration of the drug

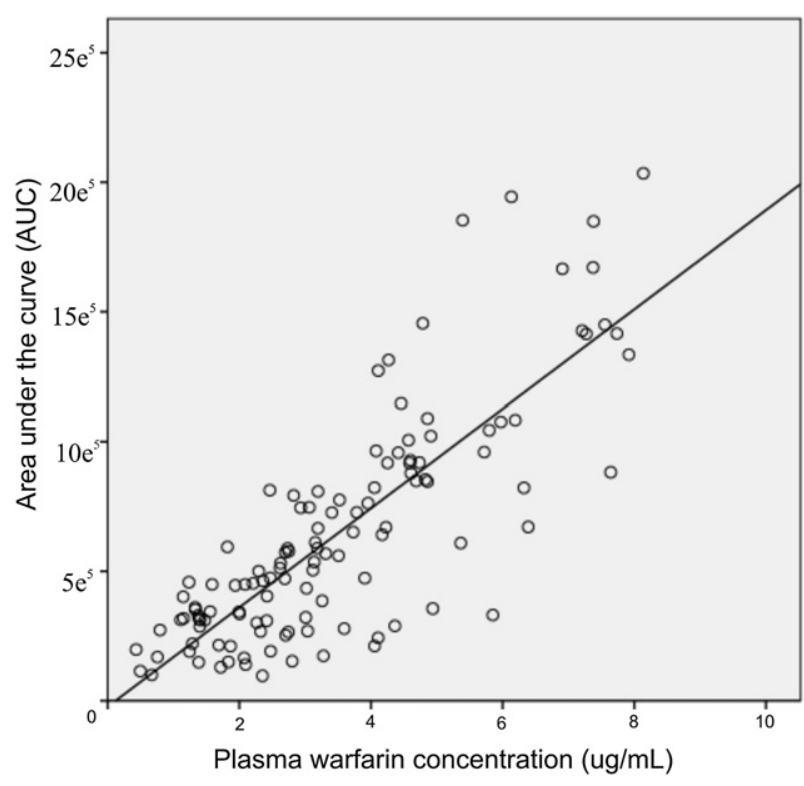

Fig. 2. Correlation of plasma warfarin concentration and peak area (AUC). 
is increased. This is one reason for apparent reduced metabolism of warfarin at higher doses (with higher metabolic ratio). Further, the higher dosage leads to warfarin related toxicities.

The warfarin treatment is problematic because of the interindividual variations in the required dose of warfarin, for which the mechanism remains elusive. The results of the individual variations some patients require a low dose (sensitive) and some patients require higher doses (resistance). Furthermore, numerous factors, including age, gender, genetic variants, illness, and drug interactions affect the plasma pharmacokinetics and drug response to warfarin. $^{22,23}$ Previous studies have explained that the genetic variation in the CYP2C9 gene that encodes the CYP2C9 enzyme leads to altered warfarin metabolism and response. ${ }^{24}$ On the other hand, only monitoring INR was limited for warfarin dose adjustment in patients with complicated situation such as bleeding or drug resistance. Therefore determination of plasma warfarin may be one of the considerations in managing patients with fluctuating INR.

The limitation of the present study was examined only the difference in metabolic ratio based on the daily dose, this will not entailed the exact metabolic variation of warfarin in our patients. Further, pharmacogenetic and pharmacokinetic studies will be conducted to confirm the influence of CYP2C9 variants on warfarin metabolism. According to the information, the patients can be categorized into different groups (poor, rapid and ultra-rapid metabolizers). In future the established method will be useful in studying the phenotype-genotype correlation of warfarin.

\section{Conclusion}

Present study showed a simple, sensitive and reliable HPLC assay for determining the plasma concentration of warfarin and 7hydroxy warfarin in patients receiving warfarin therapy. The assay was sensitive to follow warfarin pharmacokinetics in patients with stabilized warfarin therapy.

\section{Conflicts of interest}

\section{All authors have none to declare.}

\section{Acknowledgment}

The study was funded by Indian Council of Medical Research (ICMR), New Delhi, India. (ICMR Ref. No. 50/6/2010/BMS, dated 03/ 11/2010). Mrs. G. Saraswathi, Ms.S. Kalaivani, and Mrs. Revathy, are gratefully acknowledged for their technical assistance.

\section{References}

1. Harrington RA, Becker RC, Ezekowitz M, et al. Antithrombotic therapy for coronary artery disease: the Seventh ACCP Conference on Antithrombotic and Thrombolytic Therapy. Chest. 2004;126:513-548.

2. Salem DN, O'Gara PT, Madias C, Pauker SG. Valvular and structural heart disease: American College of Chest Physicians Evidence-Based Clinical Practice Guidelines (8th Edition). Chest. 2008;133:593-629.
3. Singer DE, Albers GW, Dalen JE, Go AS, Halperin JL, Manning WJ. Antithrombotic therapy in atrial fibrillation: the Seventh ACCP Conference on Antithrombotic and Thrombolytic Therapy. Chest. 2004;126:429-456.

4. Palareti G, Leali N, Coccheri S, et al. Bleeding complications of oral anticoagulant treatment: an inception-cohort, prospective collaborative study (ISCOAT). Italian Study on Complications of Oral Anticoagulant Therapy. Lancet. 1996;348:423-428.

5. Landefeld CS, Beyth RJ. Anticoagulant-related bleeding: clinical epidemiology, prediction, and prevention. Am J Med. 1993;95:315-328.

6. Horowitz B, Minor P, Morgenthaler JJ, et al. WHO Expert Committee on Biological Standardization. World Health Organ Tech Rep Ser. 2004;924:1-232.

7. Anthony CJ, Karim S, Ackroyd-Stolarz S, et al. Intensity of anticoagulation with warfarin and risk of adverse events in patients presenting to the emergency department. Ann Pharmacother. 2011;45:881-887.

8. Ghambari H, Hadjmohammadi M. Low-density solvent-based dispersive liquid-liquid microextraction followed by high performance liquid chromatography for determination of warfarin in human plasma. J Chromatogr B Analyt Technol Biomed Life Sci. 2012;899:66-71.

9. Miura M, Okuyama S, Kato S, et al. Simultaneous determination of warfarin and 7-hydroxywarfarin enantiomers by high-performance liquid chromatography with ultraviolet detection. Ther Drug Monit. 2011;33:108-114.

10. Kwon MJ, Kim HJ, Kim JW, et al. Determination of plasma warfarin concentrations in Korean patients and its potential for clinical application. Korean J Lab Med. 2009;29:515-523.

11. Sun S, Wang M, Su L, Li J, Li H, Gu D. Study on warfarin plasma concentration and its correlation with international normalized ratio. J Pharm Biomed Anal. 2006;42:218-222.

12. Lombardi R, Chantarangkul V, Cattaneo M, Tripodi A. Measurement of warfarin in plasma by high performance liquid chromatography (HPLC) and its correlation with the international normalized ratio. Thromb Res. 2003;111:281-284.

13. Kulkarni UP, Swar BD, Karnad DR, et al. A pilot study of the association of pharmacokinetic and pharmacodynamic parameters of warfarin with the dose in patients on long-term anticoagulation. Br J Clin Pharmacol. 2008;65: 787-790.

14. Huang C, Yang J, Du Y, Miao L. Measurement of free concentrations of highly protein-bound warfarin in plasma by ultra-performance liquid chromatography-tandem mass spectrometry and its correlation with the international normalized ratio. Clinica Chimica Acta. 2008;393:85-89.

15. Wadelius M, Chen LY, Eriksson N, et al. Association of warfarin dose with genes involved in its action and metabolism. Hum Genet. 2007;121:23-34.

16. Zhang Z, Fasco MJ, Huang Z, Guengerich FP, Kaminsky LS. Human cytochromes P450 1A1 and 1A2: R-warfarin as a probe. Drug Metab Dispos. 1995;23:13391345 .

17. Locatelli I, Kmetec V, Mrhar A, Grabnar I. Determination of warfarin enantiomers and hydroxylated metabolites in human blood plasma by liquid chromatography with achiral and chiral separation. J Chromatogr B Analyt Technol Biomed Life Sci. 2005;818:191-198.

18. Fasco MJ, Piper LJ, Kaminsky LS. Biochemical applications of a quantitative high-pressure liquid chromatographic assay of warfarin and its metabolites. J Chromatogr. 1977;131:365-373.

19. George M, Shewade DG, Kumar SV, Adithan C. Effect of anti-tuberculosis therapy on polymorphic drug metabolizing enzyme CYP2C9 using phenytoin as a probe drug. Indian J Pharmacol. 2012;44:485-488.

20. Subraja K, Dkhar SA, Priyadharsini R, et al. Genetic polymorphisms of CYP2C19 influences the response to clopidogrel in ischemic heart disease patients in the South Indian Tamilian population. Eur J Clin Pharmacol; 2012;. http:// dx.doi.org/10.1007/s00228-012-1381-8.

21. Baca QJ, Golan DE. Pharmacokinetics. In: Golan DE, Tashjian AH, Armstrong EJ Galanter JM, Armstrong AW, Arnaout RA, Rose HS, eds. Principles of Pharmacology: The Pathophysiologic Basis of Drug Therapy. Philadelphia: Lippincott Williams \& Wilkins, Wolters Kluwer; 2012:27-42.

22. Namazi S, Azarpira N, Hendijani F, Khorshid MB, Vessal G, Mehdipour AR. The impact of genetic polymorphisms and patient characteristics on warfarin dose requirements: a cross-sectional study in Iran. Clin Ther. 2010;32:1050-1060.

23. Herman D, Locatelli I, Grabnar I, et al. Influence of CYP2C9 polymorphisms, demographic factors and concomitant drug therapy on warfarin metabolism and maintenance dose. Pharmacogenomics J. 2005;5:193-202.

24. Rettie AE, Wienkers LC, Gonzalez FJ, Trager WF, Korzekwa KR. Impaired (S)warfarin metabolism catalysed by the R144C allelic variant of CYP2C9. Pharmacogenetics. 1994;4:39-42. 